\title{
Stage IV Uterine Corpus Cancer AJCC v6
}

National Cancer Institute

\section{Source}

National Cancer Institute. Stage IV Uterine Corpus Cancer A/CC v6. NCI Thesaurus. Code C4006.

Stage IV includes: IVA: (T4, Any N, M0); IVB: (Any T, Any N, M1). T4: Tumor invades bladder mucosa and/or bowel mucosa (bullous edema is not sufficient to classify a tumor as T4). M1: Distant metastasis (includes metastasis to abdominal lymph nodes other than para-aortic, and/or inguinal lymph nodes: excludes metastasis to vagina, pelvic serosa, or adnexa). (AJCC 6th ed.) - 2003 